\title{
Assessment of retinal vascular oxygenation and morphology at stages of diabetic retinopathy in African Americans
}

\author{
Sarah L. Garvey ${ }^{1}$, Maziyar M. Khansari ${ }^{2,3}$, Xuejuan Jiang ${ }^{2}$, Rohit Varma ${ }^{4}$ and Mahnaz Shahidi ${ }^{*}$
}

\begin{abstract}
Background: Diabetic retinopathy (DR) is a microvascular complication of diabetes and a leading cause of blindness in working-age adults. The likelihood of visual impairment associated with DR is two-fold higher in the African-American (AA) compared to non-Hispanic white. Although alterations in retinal vessel oxygenation and morphology have been reported in DR, there is limited knowledge about these vascular changes in AA subjects. The purpose of the current study was to investigate alterations in retinal vascular oxygen saturation $\left(\mathrm{SO}_{2}\right)$, vessel diameter (D) and tortuosity at severity stages of DR in AA subjects.

Methods: A nested case-control study of 56 AA subjects was conducted. Right eyes were grouped as non-diabetic (ND) $(N=26)$, no clinical DR (NDR) ( $N=19)$, or moderate/severe non-proliferative DR (NPDR) $(N=11)$. Imaging was performed using a commercially available scanning laser ophthalmoscope. Images were analyzed to determine retinal arterial and venous $\mathrm{SO}_{2}\left(\mathrm{SO}_{2 \mathrm{~A}}\right.$ and $\left.\mathrm{SO}_{2 \mathrm{~V}}\right)$, diameter $\left(\mathrm{D}_{\mathrm{A}}\right.$ and $\left.\mathrm{D}_{\mathrm{V}}\right)$, and vessel tortuosity index $(\mathrm{VTI})\left(\mathrm{VTI} \mathrm{A}_{\mathrm{A}}\right.$ and VTIV).
\end{abstract}

Results: $\mathrm{SO}_{2 V}$ and $\mathrm{D}_{V}$ were higher in NPDR compared to ND and NDR groups $(P<0.05)$. There were no significant differences in $\mathrm{SO}_{2 \mathrm{~A}}$ and $\mathrm{D}_{\mathrm{A}}$ among ND, NDR, and NPDR groups $(P>0.8)$. Maximum $\mathrm{VTI}_{\mathrm{A}}$ was higher in diabetics (NDR and NPDR) compared to non-diabetics $(P<0.03)$. There was no significant difference in maximum $V T I_{V}$ among the 3 groups $(P=0.5)$.

Conclusions: The findings advance our understanding of DR pathophysiology in the AA population and may propel identification of race-specific retinal vascular biomarkers for improved diagnosis and monitoring of DR.

Keywords: Diabetic retinopathy, African American, Oxygenation, Tortuosity, Image analysis

\section{Background}

Diabetic retinopathy (DR), a microvascular complication of diabetes, is one of the leading causes of blindness in the United States [1]. DR subjects are 29 times more likely to go blind as compared with non-diabetics of similar age and gender [2]. While DR has been associated with increased duration of diabetes and HbAlc

\footnotetext{
* Correspondence: mshahidi@usc.edu

${ }^{2}$ Department of Ophthalmology, University of Southern California, 1450 San Pablo Street, Los Angeles, California 90033, USA

Full list of author information is available at the end of the article
}

levels [3], limited knowledge is available regarding the development of retinal pathologies. The established risk factors partially explain the pathogenesis of DR [4], therefore identifying additional quantifiable markers becomes important in better understanding the development, diagnosis and management of DR. According to the Model Reporting Area (MRA) blindness registry data, a comparison of age-adjusted rates of legal blindness associated with DR demonstrated a two-fold increased likelihood of blindness for predominantly African-American (AA) as compared to non-Hispanic

(c) The Author(s). 2020 Open Access This article is licensed under a Creative Commons Attribution 4.0 International License, which permits use, sharing, adaptation, distribution and reproduction in any medium or format, as long as you give appropriate credit to the original author(s) and the source, provide a link to the Creative Commons licence, and indicate if changes were made. The images or other third party material in this article are included in the article's Creative Commons licence, unless indicated otherwise in a credit line to the material. If material is not included in the article's Creative Commons licence and your intended use is not permitted by statutory regulation or exceeds the permitted use, you will need to obtain permission directly from the copyright holder. To view a copy of this licence, visit http://creativecommons.org/licenses/by/4.0/ The Creative Commons Public Domain Dedication waiver (http://creativecommons.org/publicdomain/zero/1.0/) applies to the data made available in this article, unless otherwise stated in a credit line to the data. 
white (NHW) [5]. There has also been a rise in the incidence of diabetes in AA population [6, 7]. Type 2 diabetics constitute $95 \%$ of AA with diabetes, and the incidence of type 2 diabetes in AA is 50 to $100 \%$ greater than in NHW [8]. Despite the fact that racial minorities in the United States have experienced an increased rate of diabetes, race-specific data on the development of blindness and DR in AA populations is scarce.

In addition to increased prevalence of diabetes, AA experience higher rates of morbidity and mortality relative to NHW with diabetes [9]. This includes an increased risk of diabetes-related microvascular complications such as end-stage nephropathy, diabetic retinopathy, and peripheral neuropathy. The increased incidence of diabetes-related limb amputations and end-stage nephropathy in the AA population is well-documented [10]. However, there is comparably little data regarding the racial differences in the rate of DR. Most of the existing studies on the population-based epidemiology and risk factors for developing DR have involved insufficient number of AA, and therefore have been unable to provide race-specific details regarding the development of this disease in this population [11]. Nevertheless, the Salisbury Eye Evaluation Study [12] provided comparative race-specific data for visual impairment due to DR in AA and NHW. They found that AA were 4 times as likely to develop DR as compared with NHW, and that DR accounted for $17 \%$ of vision impairment as compared with $8 \%$ in NHW. They concluded that DR is the second leading cause of vision impairment in the AA population. These results reflect the substantial impact of DR and vision loss in AA and necessity of further investigation.

One quantifiable marker of DR is based on assessment of the retinal vasculature. Recent studies have shown that changes in retinal vessel caliber and dimension are linked to diabetes [13-15]. Furthermore, changes in retinal hemodynamics such as decreased blood flow, disruption of vascular endothelium, and increased vascular endothelial growth factor (VEGF) affect retinal vessel tortuosity $[16,17]$. However, reported changes in retinal blood flow in DR have been variable [18-20]. Increased retinal vessel tortuosity has been reported in diabetes $[21,22]$ and increased retinal arteriolar tortuosity was found to be associated with a high HbA1c levels in patients with type 1 diabetes, even in young patients with no DR. [23] However, limited quantitative data is available regarding tortuosity of retinal vessels in AA at stage of DR.

Another vital component of the pathophysiology of DR is abnormal retinal oxygenation [24]. This was determined by the treatment of neovascularization with VEGF inhibitors and vascular non-perfusion on fluorescein angiography in hypoxia-induced states [25, 26].
Oxygenation of the retina depends on the rate of blood flow and oxygen concentration within blood. Previous studies have shown that blood flow velocity is decreased in retinal arteries and veins in early diabetes [27]. Recent studies have reported increase in vessel diameter in diabetic subjects [28-30]. Meanwhile the concentrations of oxygen in the arterial and venous blood are directly related to the oxygen saturations of hemoglobin $\left(\mathrm{SO}_{2}\right)$. $\mathrm{SO}_{2}$ can be measured by comparing absorption of light by oxy- and deoxy-hemoglobin at 2 different wavelengths. Several studies have demonstrated alterations in retinal vascular $\mathrm{SO}_{2}$ due to diabetes [31]. However, these studies featured a population that was mostly NHW and homogeneous, though one recent study reported an effect of race on $\mathrm{SO}_{2}$ measured in DR subjects [24]. The purpose of the current study was to investigate alterations in retinal vascular $\mathrm{SO}_{2}$, diameter and tortuosity at stages of DR in an AA cohort from the African American Eye Disease Study (AFEDS).

\section{Methods \\ Subjects}

The study was approved by the Institutional Review Board of the University of Southern California and was conducted in accordance to the Tenets of Declaration of Helsinki. The study included 56 AA subjects (female/ male $=60 \% / 40 \%$ ) who participated in the AFEDS, with ages ranging from 40 to 87 years old. By July 2017, a total of 14 subjects with moderate/severe NPDR and 18 diabetic subjects without clinical DR (NDR) were identified to have images acquired by Optos Daytona in the AFEDS study. Images were reviewed by an ophthalmologist and those with poor quality due to media opacities or artifacts (e.g. eye lash, dust spots) were excluded. All diabetic subjects were considered to have type II diabetes based on not being insulin dependent or had been diagnosed with diabetes after 30 years of age. The duration of diabetes was calculated as the difference between the year of diagnosis (self-reported) and the year of vision examination in AFEDS. An equal number of subjects $(N=32)$ without diabetes (ND) were randomly selected from the AFEDS study. Data on vascular oxygen saturation and vessel dimeter were available in $26 \mathrm{ND}$, 19 NDR, and 11 NPDR. Only 2 NPDR subjects had macular edema. DR severity was determined as part of the AFEDS study in a masked manner at the Grading Center of the Singapore Eye Institute, using modifications of the Early Treatment Diabetic Retinopathy Study [32]. All right eyes were free of other major ocular diseases and treatments. Subjects' demographics including age, mean arterial pressure (MAP) $((\mathrm{SBP}+2 \mathrm{DBP}) / 3)$, glycated hemoglobin (HbA1C), intraocular pressure (IOP), and axial length (AL) were recorded by trained 
ophthalmic technicians using standardized protocols [33].

\section{Vascular oxygen saturation and vessel diameter}

Retinal vascular oxygen saturation $\left(\mathrm{SO}_{2}\right)$ was measured by our previously developed method [24] using retinal images acquired at two wavelengths $(532 \mathrm{~nm}$ and 633 $\mathrm{nm}$ ) by a commercially available scanning laser ophthalmoscope (Optos, Daytona). Our previous study used images from the previous model of the instrument (Optos 200X). From the retinal images, a region of interest was identified within a circumpapillary region centered on the optic nerve head $(\mathrm{ONH})$ and extended between 2 and $3 \mathrm{ONH}$ radii, as indicated by the green circles in Fig. 1a. As previously described [24, 34, 35], vessels were detected using Frangi vesselness filtering [36] and optical density (OD) was determined for each vessel per imaging wavelength as the average ratio of the intensity values inside to outside the vessel. Optical density ratio (ODR) was calculated as $\mathrm{OD}_{633} / \mathrm{OD}_{532}$. A linear conversion was used to calculate arterial and venous $\mathrm{SO}_{2}$ $\left(\mathrm{SO}_{2 \mathrm{~A}}\right.$ and $\left.\mathrm{SO}_{2 \mathrm{~V}}\right)$ from the ODR measurements. Diameter (D) of each vessel segment was measured by our previously described method. Distance transformation was used to detect vessel centerlines. Intensity profiles perpendicular to the vessel centerline were obtained at every 7 pixels along the vessels. Full width at half maximum of the intensity profiles were determined from each of the vessel segments and averaged to provide arterial and venous $\mathrm{D}\left(\mathrm{D}_{\mathrm{A}}\right.$ and $\left.\mathrm{D}_{\mathrm{V}}\right)$ measurements.

\section{Vessel tortuosity}

Vessel tortuosity was measured based on our previously validated vessel tortuosity index (VTI) [34, 37] within a circumpapillary region that extended between 1.5 and 5 $\mathrm{ONH}$ radii, as indicated by yellow circles in Fig. 1b. Retinal vessels were detected using Frangi vesselness filtering to generate a binary image. The endpoints of the vessels were selected on the binary image and distance transformation was used to extract the vessel centerline between the end points. VTI was determined based combination on several tortuosity features as explained previously [37]. Mean and maximum arterial and venous VTI $\left(\mathrm{VTI}_{\mathrm{A}}\right.$ and $\left.\mathrm{VTI}_{\mathrm{V}}\right)$ were determined.

\section{Data analysis}

Statistical analysis was performed with SAS 9.4 (SAS Institute Inc., Cary, North Carolina, USA). Since this was a pilot study in a limited cohort of subjects, sample size was not pre-determined for optimal power. Demographics were compared between groups of subjects using ttest or chi-square test. Linear regression was used to determine the effect of DR stage (ND, NDR, NPDR) on D, $\mathrm{SO}_{2}$, VTI after adjusting for covariates including age, MAP, HbA1C, IOP and AL. There was no significant correlation between duration of diabetes and retinal vascular metrics in this sample of diabetic subjects. Statistical tests were 2 -sided, and significance was accepted at $P \leq 0.05$.

\section{Results}

Subjects' demographics are summarized in Table 1. There were no statistically significant differences in age, MAP, IOP, or axial length among the 3 groups $(P>0.1)$. HbA1C level was higher in the NDR and NPDR as compared to ND $(P<0.001)$. The duration of diabetes was not significantly different between NDR and NPDR subjects $(P=0.35)$.

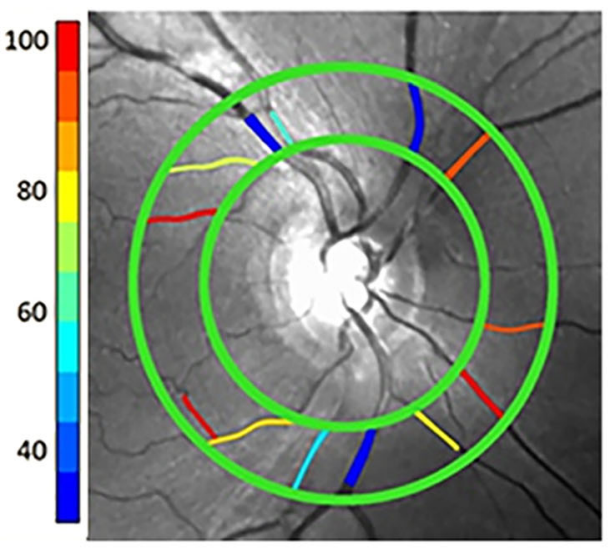

(a)

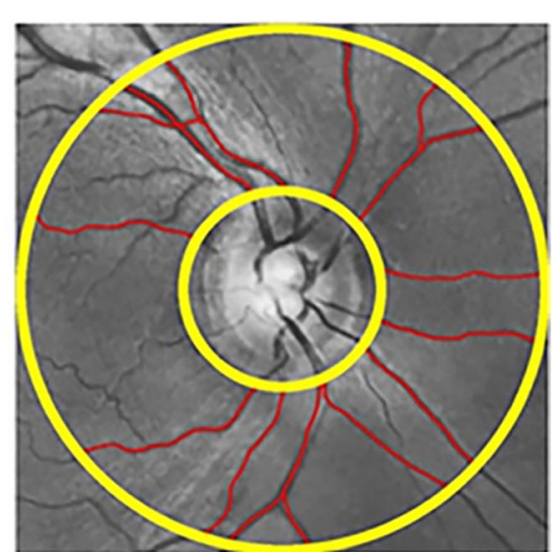

(b)

Fig. 1 Example of a retinal image at $532 \mathrm{~nm}$ in a non-diabetic subject. (a) Oxygen saturation measurements in retinal arteries and veins are displayed in pseudo color. Color bar represents hemoglobin oxygen saturation in units of percent. (b) Retinal vessel centerlines (red lines) used for tortuosity measurements are overlaid on the retinal image 
Table 1 Subjects' demographics. ND, NDR, and NPDR stand for non-diabetic, diabetic without diabetic retinopathy, and moderate/ severe non-proliferative diabetic retinopathy, respectively. MAP is mean arterial pressure, HbA1C is glycosylated hemoglobin, and IOP is intraocular pressure

\begin{tabular}{lllll}
\hline & ND $(\boldsymbol{N}=\mathbf{2 6})$ & NDR $(\boldsymbol{N}=\mathbf{1 9})$ & NPDR $(\boldsymbol{N}=\mathbf{1 1})$ & $P$-value for group difference \\
\hline Age (years) & $57 \pm 13$ & $64 \pm 12$ & $57 \pm 13$ & 0.21 \\
MAP $(\mathbf{m m H g})$ & $97 \pm 14$ & $95 \pm 11$ & $95 \pm 17$ & 0.87 \\
HbA1C $(\%)$ & $5.6 \pm 0.4$ & $7.4 \pm 1.4$ & $8.5 \pm 2.0$ & $<0.001$ \\
IOP $(\mathbf{m m H g})$ & $13.9 \pm 2.9$ & $16.0 \pm 4.1$ & $15.3 \pm 2.6$ & 0.11 \\
Axial Length (mm) & $23.6 \pm 0.9$ & $23.5 \pm 0.9$ & $23.3 \pm 0.3$ & 0.52 \\
Duration of Diabetes (years) & & $7.5 \pm 5.4$ & $10.4 \pm 9.4$ & 0.35 \\
\hline
\end{tabular}

Mean and standard deviation (SD) of retinal arterial and venous $\mathrm{SO}_{2}$ are shown in Fig. 2. Mean and $\mathrm{SD}$ of $\mathrm{SO}_{2 \mathrm{~A}}$ among $\mathrm{ND}, \mathrm{NDR}$, and NPDR groups were $89 \pm$ $21 \%, 88 \pm 21 \%$ and $89 \pm 20 \%$, respectively. $\mathrm{SO}_{2 \mathrm{~V}}$ were $54 \pm 11 \%, 53 \pm 13 \%$ and $63 \pm 11 \%$ in ND, NDR, and NPDR groups, respectively. There was no significant difference in $\mathrm{SO}_{2 \mathrm{~A}}$ among ND, NDR, and NPDR groups $(P=0.96)$, while $\mathrm{SO}_{2 \mathrm{~V}}$ was higher in NPDR compared to ND and NDR groups $(P<0.05)$.

Mean and SD of retinal arterial and venous $\mathrm{D}$ are shown in Fig. 3. $\mathrm{D}_{\mathrm{A}}$ in ND, NDR, and NPDR groups were $87 \pm 10 \mu \mathrm{m}, 85 \pm 12 \mu \mathrm{m}$ and $88 \pm 6 \mu \mathrm{m}$, respectively. $D_{V}$ were $105 \pm 15 \mu \mathrm{m}, 102 \pm 13 \mu \mathrm{m}$ and $125 \pm 20 \mu \mathrm{m}$ in ND, NDR and NPDR groups, respectively. There was no significant difference in $\mathrm{D}_{\mathrm{A}}$ among ND, NDR, and NPDR groups $(P=0.89)$, while $\mathrm{D}_{\mathrm{V}}$ was higher in NPDR compared to ND and NDR groups $(P<0.05)$.

Mean and SD of retinal arterial and venous maximum VTI are shown in Fig. 4. Arterial maximum VTI among ND, NDR, and NPDR groups were $0.43 \pm 0.26,0.28 \pm$
0.19 and $0.65 \pm 0.51$, respectively. In venules, maximum VTI were $0.44 \pm 0.25,0.40 \pm 0.28$ and $0.54 \pm 0.32$ in ND, $\mathrm{NDR}$, and NPDR groups, respectively. Maximum $\mathrm{VTI}_{\mathrm{A}}$ was higher in NDR and NPDR compared to ND $(P<$ $0.03)$. There was no significant difference in maximum $\mathrm{VTI}_{\mathrm{V}}$ among groups $(P=0.54)$.

\section{Discussion}

In the current study, we demonstrated increased venous $\mathrm{SO}_{2}$, venous diameter, and arterial tortuosity in moderate/severe NPDR in AA subjects. To our knowledge, this is the first report in literature assessing retinal vascular oxygenation and vessel morphology at stages of DR, specifically in AA subjects. The findings have the potential to stimulate future studies aimed at identification of race-specific biomarkers that may help reduce the risk of vision loss due to $\mathrm{DR}$ in the AA population.

The findings of increased retinal venous $\mathrm{SO}_{2}$ in NPDR, but no significant difference in arterial $\mathrm{SO}_{2}$ among DR stages in AA population are consistent with reports of

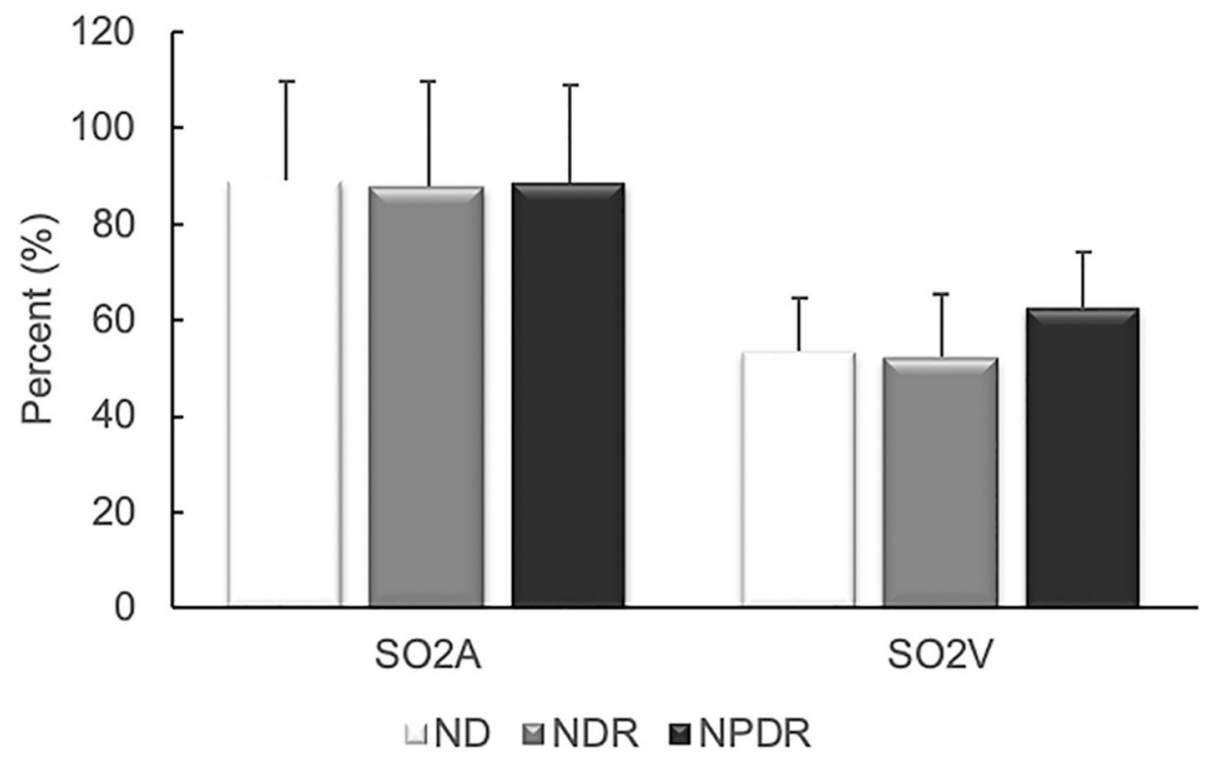

Fig. 2 Mean and standard deviation of retinal arterial and venous $\mathrm{SO}_{2}$. There was no significant difference in $\mathrm{SO}_{2 \mathrm{~A}}$ among $\mathrm{ND}, \mathrm{NDR}$, and $\mathrm{NPDR}$ groups, while $\mathrm{SO}_{2 V}$ was higher in NPDR compared to ND and NDR groups 


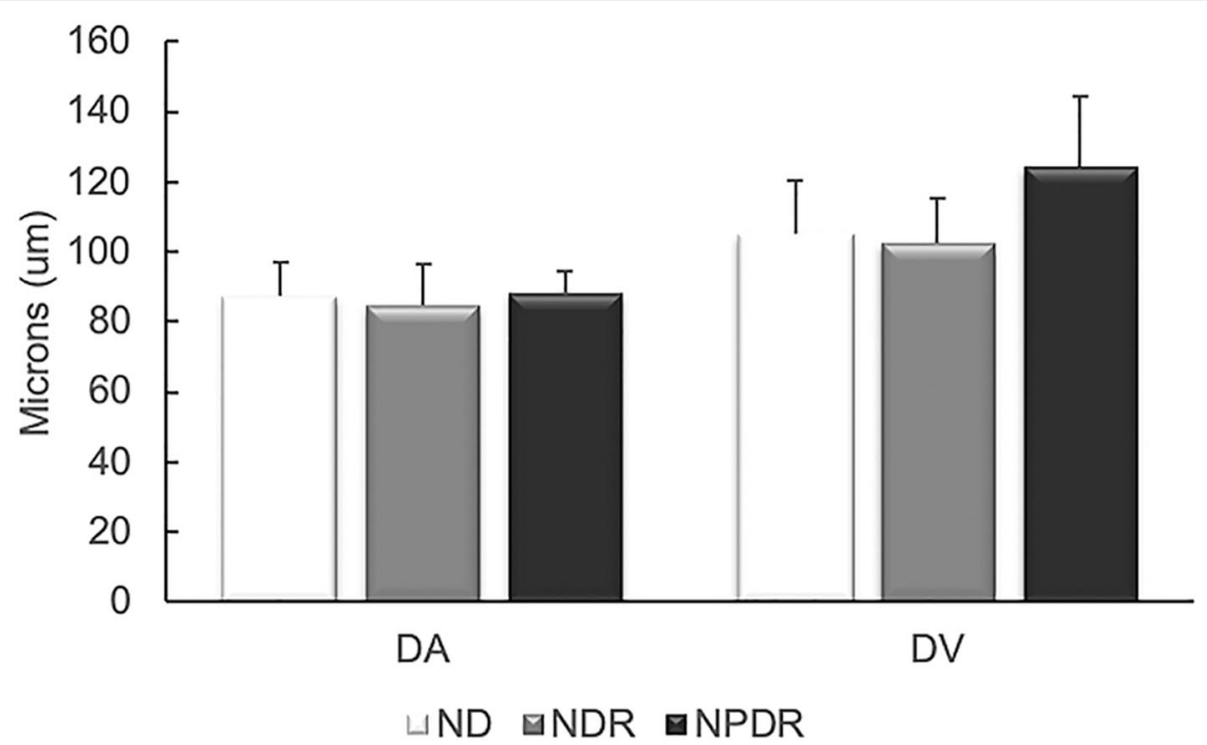

Fig. 3 Mean and standard deviation of retinal arterial and venous D. There was no significant difference in $D_{A}$ among ND, NDR, and NPDR groups, while $D_{v}$ was higher in NPDR compared to ND and NDR groups

previous studies conducted in primarily white populations $[24,38,39]$. However, other studies found no difference in retinal venous $\mathrm{SO}_{2}$ between diabetics with no DR and non-diabetics [31, 40]. Variations in findings are likely due to methodologies, subject demographics, and level of retinopathy.

We found that retinal venous diameter was increased in NPDR, while arterial diameter was not different among DR stages. This finding is in agreement with numerous studies that showed venous vasodilation and variable arterial diameter changes dependent on DR stage [41-47]. This presumable biphasic arterial diameter changes may contribute to the lack of significant findings in arterial diameter in the current study. The finding of increased retinal arterial tortuosity with DR stage is consistent with a previous report [48]. Another study demonstrated that DR subjects with macular edema had elongated and more tortuous retinal vessels than their nondiabetic counterparts [21]. The pathophysiology of why vessels become more tortuous,

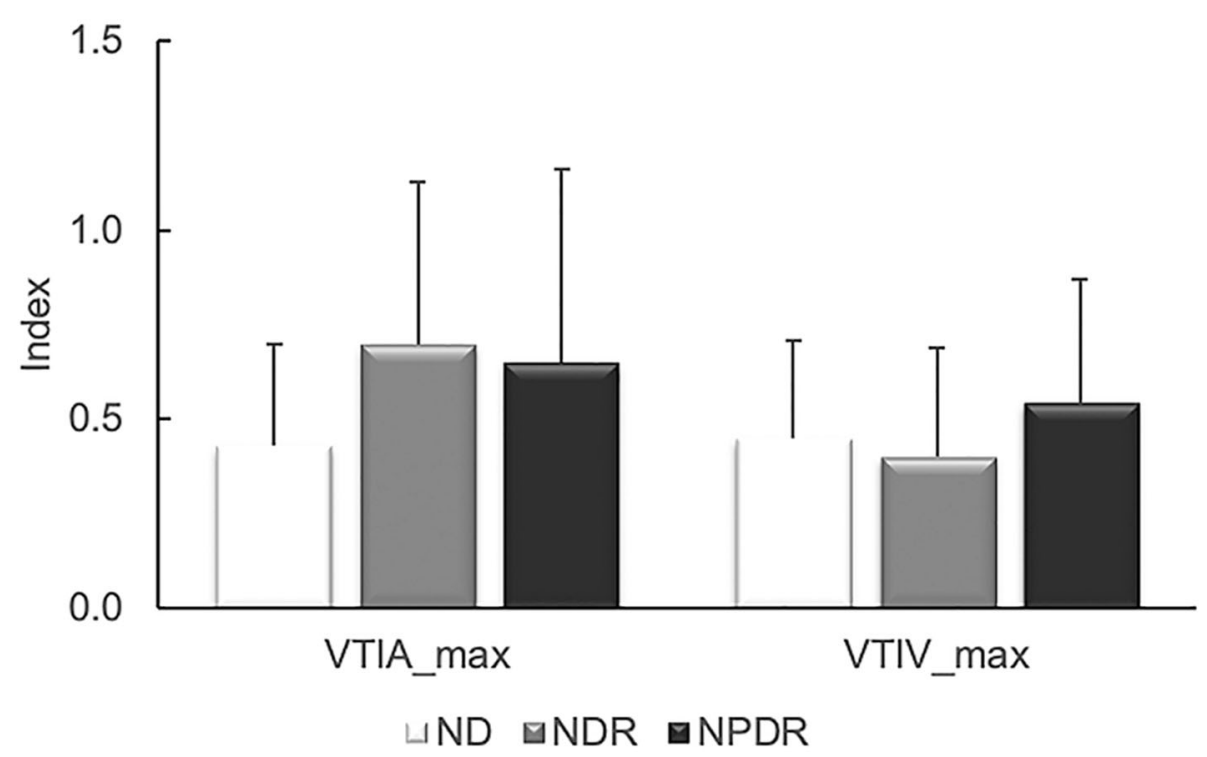

Fig. 4 Mean and standard deviation of retinal arterial and venous maximum VTI. Maximum $\mathrm{VTI}_{\mathrm{A}}$ was higher in NDR and NPDR compared to ND, whereas there was no significant difference in maximum VTIV among groups 
however, remains unclear. In addition to the theory of increased VEGF secretion due to hypoxia [49], increased vessel tortuosity may occur due to blood flow disturbances leading to loss of vessel endothelium and subsequent failure to maintain the integrity of the vessel wall [50]. Furthermore, this increased fragility of the vessel wall can predispose to hemorrhage which is commonly observed in DR. [51]

The current study is the first report of alterations in retinal vascular $\mathrm{SO}_{2}$ in diabetic AA subjects. Although the effect of race on retinal oximetry data has not been previously investigated, a dependence of $\mathrm{SO}_{2 \mathrm{~A}}$ on race was demonstrated in a study of both AA and white diabetic subjects [24]. It is not clear whether this finding is due to biological or pigmentation differences between races. However, since the statistical model generated in the previous study adjusted for pigmentation, it is likely that other factors may account for the observed racial differences. Of note, in the current study, the calibration factor used for conversion of light absorption ratios to oxygen saturation was derived based on healthy AA subjects, thus accounted for pigmentation. Comparative studies of retinal vessel diameter and tortuosity between diabetic AA and white subjects are not available. Genetic and racial factors that determine retinal vessel caliber and compliance to adjust to transient blood flow changes may play a role in the susceptibility of subjects for development of DR. For example, a previous genome-wide association study of subjects of European ancestry showed genetic loci associated with retinal vessel diameter [52]. Future studies are needed to identify and compare factors associated with retinal vessel metrics in AA and white populations.

There is limited knowledge of factors that contribute to the observed difference in the prevalence of DR according to race. A large study conducted in the AA diabetic population showed a lack of association between proportion of African ancestry and PDR after adjustment for clinical, demographic, and socioeconomic factors [53]. Furthermore, no genetic loci associated with PDR was identified using admixture mapping in AA subjects. In a case-control study of diabetic AA subjects, duration of diabetes, systolic hypertension and insulin use were found to be risk factors for the development of PDR [54]. Moreover, P-selectin plasma level was associated with DR in the AA population based on both serologic and genetic data [55]. Future studies are needed to investigate association of retinal vascular metrics with stages of DR in the AA population. Such studies have the potential to identify race-specific biomarkers for staging and monitoring progression of DR, thus providing more targeted and effective clinical management of DR in AA subjects.
The current study had limitations. First, measurements were not derived from exactly the same retinal vessel segments and were restricted to a region close to the $\mathrm{ONH}$, thus changes distal to the $\mathrm{ONH}$ and in smaller branching vessels were not considered. Second, potential confounders, such as macular edema were not considered which may have contributed to inter-subject measurement variability. Third, imaging was performed with a commercial instrument and the wavelengths were not optimized for oximetry, though previous studies have been performed with a similar instrument [24, 56, 57]. Fourth, data from different racial populations were not available for direct comparison. Fifth, the sample size was small, thus comparisons in which no significant difference was detected may have been due to lack of statistical power $(<15 \%)$. Future studies are needed for assessment of retinal vascular oxygenation and vessel morphology in larger and multi-racial cohorts to expand the current findings and potentially identify race-specific biomarkers at progressive stages of DR.

\section{Conclusions}

Overall, the current study showed alterations in retinal vascular oxygenation and morphology in AA subjects at stages of DR. The findings advance our understanding of DR pathophysiology in the AA population and propel future studies to provide race-specific biomarkers for assessment of DR.

\section{Abbreviations}

DR: Diabetic retinopathy; AA: African-American; SO2: Oxygen saturation; D: Diameter; ND: Non-diabetic; NDR: No clinical DR; NPDR: Moderate/severe non-proliferative DR; VTI: Vessel tortuosity index; MRA: Model reporting area; NHW: Non-hispanic white; VEGF: Vascular endothelial growth factor; AFED S: African-American eye disease study; HbA1C: Glycated hemoglobin; IOP: Intraocular pressure; MAP: Mean arterial pressure; ONH: Optic nerve head; ODR: Optical density ratio; SD: Standard deviation

\section{Acknowledgements}

None.

\section{Authors' contributions}

MS, corresponding author, study design and manuscript preparation. SG, MK, data analysis and manuscript revision. RV, data collection and interpretation. $\mathrm{XJ}$, study design, data collection, statistical analysis and manuscript revision. All authors have read and approved the manuscript.

\section{Funding}

This study was supported by NIH grants DK104393 (MS), EY029220 (MS), EY030115 (MS), EY028721 (XJ), and EY023575 (RV); and Research to Prevent Blindness Foundation. The funders did not have a role in the design and conduct of the study.

\section{Availability of data and materials}

The data generated in the current study are not publicly available due to privacy and security of patients, but can be made available from the corresponding author on reasonable request.

\section{Ethics approval and consent to participate}

The study was approved by the institutional review board/ethics committee of the University of Southern California Health Sciences Review Board (IRB\#: HS-13-0030). The study complies with the Health Insurance Portability and 
Accountability Act of 1996 and adheres to all Declaration of Helsinki guidelines. All study participants provided informed and written consent.

\section{Consent for publication}

Not Applicable.

\section{Competing interests}

The authors declare no conflict of interest.

\section{Author details}

${ }^{1}$ College of Medicine, University of Illinois at Chicago, Chicago, IL, USA. 2Department of Ophthalmology, University of Southern California, 1450 San Pablo Street, Los Angeles, California 90033, USA. '3Stevens Neuroimaging and Informatics Institute, University of Southern California, Los Angeles, CA, USA. ${ }^{4}$ Southern California Eye Institute, CHA Hollywood Presbyterian Medical Center, Los Angeles, CA, USA.

\section{Received: 28 August 2019 Accepted: 10 July 2020}

\section{Published online: 18 July 2020}

\section{References}

1. Stitt AW, Curtis TM, Chen M, et al. The progress in understanding and treatment of diabetic retinopathy. Prog Retin Eye Res. 2016;51:156-86.

2. Aubert R. Diabetes in America: National Institute of Diabetes and Digestive and Kidney Diseases; 1995.

3. Cheung N, Mitchell P, Wong TY. Diabetic retinopathy. Lancet. 2010;376:124-36.

4. Hirsch IB, Brownlee M. Beyond hemoglobin A1c--need for additional markers of risk for diabetic microvascular complications. JAMA. 2010;303: 2291-2.

5. Harris EL, Sherman SH, Georgopoulos A. Black-white differences in risk of developing retinopathy among individuals with type 2 diabetes. Diabetes Care. 1999:22:779-83.

6. Weiss DM, Casten RJ, Leiby BE, et al. Effect of Behavioral intervention on dilated fundus examination rates in older African American individuals with diabetes mellitus: a randomized clinical trial. JAMA Ophthalmol. 2015;133: 1005-12.

7. Zhang X, Cotch MF, Ryskulova A, et al. Vision health disparities in the United States by race/ethnicity, education, and economic status: findings from two nationally representative surveys. Am J Ophthalmol. 2012;154:S53-62 e51.

8. Lipton RB, Liao Y, Cao G, Cooper RS, McGee D. Determinants of incident non-insulin-dependent diabetes mellitus among blacks and whites in a national sample. The NHANES I epidemiologic follow-up study. Am J Epidemiol. 1993:138:826-39.

9. Rasooly RS, Akolkar B, Spain LM, Guill MH, Del Vecchio CT, Carroll LE. The National Institute of Diabetes and Digestive and Kidney Diseases central repositories: a valuable resource for nephrology research. Clin J Am Soc Nephrol. 2015;10:710-5.

10. Crook ED, Patel SR. Diabetic nephropathy in African-American patients. Curr Diab Rep. 2004;4(6):455-61. https://doi.org/10.1007/s11892-004-0056-y.

11. Baker RS. Diabetic retinopathy in African Americans: vision impairment, prevalence, incidence, and risk factors. Int Ophthalmol Clin. 2003;43:105-22.

12. Munoz B, West SK, Rubin GS, et al. Causes of blindness and visual impairment in a population of older Americans: the Salisbury eye evaluation study. Arch Ophthalmol. 2000;118:819-25.

13. Grauslund J, Hodgson L, Kawasaki R, Green A, Sjolie AK, Wong TY. Retinal vessel calibre and micro- and macrovascular complications in type 1 diabetes. Diabetologia. 2009;52:2213-7.

14. Nguyen TT, Wang JJ, Wong TY. Retinal vascular changes in pre-diabetes and prehypertension: new findings and their research and clinical implications. Diabetes Care. 2007:30:2708-15.

15. Yau JW, Kawasaki R, Islam FM, et al. Retinal fractal dimension is increased in persons with diabetes but not impaired glucose metabolism: the Australian diabetes, obesity and lifestyle (AusDiab) study. Diabetologia. 2010;53:2042-5.

16. Hartnett ME, Martiniuk D, Byfield G, Geisen P, Zeng G, Bautch VL. Neutralizing VEGF decreases tortuosity and alters endothelial cell division orientation in arterioles and veins in a rat model of ROP: relevance to plus disease. Invest Ophthalmol Vis Sci. 2008:49:3107-14.

17. Paques M, Krivosic V, Girmens JF, Giraud C, Sahel J, Gaudric A. Decreased venous tortuosity associated with resolution of macular edema after intravitreal injection of triamcinolone. Retina. 2005;25:1099-101.
18. Palochak CMA, Lee HE, Song J, Geng A, Linsenmeier RA, Burns SA, Fawzi AA Retinal Blood Velocity and Flow in Early Diabetes and Diabetic Retinopathy Using Adaptive Optics Scanning Laser Ophthalmoscopy. J Clin Med. 2019; 8(8):1165. https://doi.org/10.3390/jcm8081165.

19. Pemp B, Schmetterer L. Ocular blood flow in diabetes and age-related macular degeneration. Can J Ophthalmol. 2008:43:295-301.

20. Pournaras CJ, Rungger-Brandle E, Riva CE, Hardarson SH, Stefansson E. Regulation of retinal blood flow in health and disease. Prog Retin Eye Res. 2008:27:284-330.

21. Kristinsson JK, Gottfredsdottir MS, Stefansson E. Retinal vessel dilatation and elongation precedes diabetic macular oedema. Br J Ophthalmol. 1997;81: 274-8.

22. Robison WG Jr, Laver NM, Jacot JL, Glover JP. Sorbinil prevention of diabetic-like retinopathy in the galactose-fed rat model. Invest Ophthalmol Vis Sci. 1995:36:2368-80.

23. Sasongko MB, Wang JJ, Donaghue KC, et al. Alterations in retinal microvascular geometry in young type 1 diabetes. Diabetes Care. 2010;33: 1331-6.

24. Blair NP, Wanek J, Felder AE, et al. Retinal Oximetry and vessel diameter measurements with a commercially available scanning laser ophthalmoscope in diabetic retinopathy. Invest Ophthalmol Vis Sci. 2017:58: 5556-63.

25. Ernst BJ, Garcia-Aguirre G, Oliver SC, Olson JL, Mandava N, Quiroz-Mercado $H$. Intravitreal bevacizumab versus panretinal photocoagulation for treatment-naive proliferative and severe nonproliferative diabetic retinopathy. Acta Ophthalmol. 2012;90:e573-4.

26. Simunovic MP, Maberley DA. Anti-vascular endothelial growth factor therapy for proliferative diabetic retinopathy: a systematic review and metaanalysis. Retina. 2015;35:1931-42

27. Burgansky-Eliash Z, Barak A, Barash H, et al. Increased retinal blood flow velocity in patients with early diabetes mellitus. Retina. 2012;32:112-9.

28. Alibrahim E, Donaghue KC, Rogers S, et al. Retinal vascular caliber and risk of retinopathy in young patients with type 1 diabetes. Ophthalmology. 2006:113:1499-503.

29. Falck A, Laatikainen L. Retinal vasodilation and hyperglycaemia in diabetic children and adolescents. Acta Ophthalmol Scand. 1995:73:119-24.

30. Yau JW, Xie J, Lamoureux E, et al. Retinal microvascular calibre and risk of incident diabetes: the multi-ethnic study of atherosclerosis. Diabetes Res Clin Pract. 2012;95:265-74.

31. Khoobehi B, Firn K, Thompson H, Reinoso M, Beach J. Retinal arterial and venous oxygen saturation is altered in diabetic patients. Invest Ophthalmol Vis Sci. 2013;54:7103-6.

32. Early Treatment Diabetic Retinopathy Study Research G. Grading diabetic retinopathy from stereoscopic color fundus photographs - an extension of the modified Airlie house classification: ETDRS report number 10. Ophthalmology. 2020;127:S99-S119.

33. McKean-Cowdin R, Fairbrother-Crisp A, Torres M, et al. The African American eye disease study: design and methods. Ophthalmic Epidemiol. 2018;25:306-14.

34. Khansari MM, Garvey SL, Farzad S, Shi Y, Shahidi M. Relationship between retinal vessel tortuosity and oxygenation in sickle cell retinopathy. Int J Retina Vitreous. 2019:5:47.

35. Felder AE, Wanek J, Blair NP, Shahidi M. Inner retinal oxygen extraction fraction in response to light flicker stimulation in humans. Invest Ophthalmol Vis Sci. 2015;56:6633-7.

36. Frangi A, Niessen W, Vincken K, Viergever M. Multiscale vessel enhancement filtering. International conference on medical image computing and computer-assisted intervention. Berlin: Springer; 1998. p. 130-7.

37. Khansari MM, O'Neill W, Lim J, Shahidi M. Method for quantitative assessment of retinal vessel tortuosity in optical coherence tomography angiography applied to sickle cell retinopathy. Biomed Opt Express. 2017;8: 3796-806.

38. Hammer M, Vilser W, Riemer T, et al. Diabetic patients with retinopathy show increased retinal venous oxygen saturation. Graefes Arch Clin Exp Ophthalmol. 2009:247:1025-30

39. Kashani AH, Lopez Jaime GR, Saati S, Martin G, Varma R, Humayun MS Noninvasive assessment of retinal vascular oxygen content among normal and diabetic human subjects: a study using hyperspectral computed tomographic imaging spectroscopy. Retina. 2014;34:1854-60.

40. Felder AE, Wanek J, Blair NP, et al. The effects of diabetic retinopathy stage and light flicker on inner retinal oxygen extraction fraction. Invest Ophthalmol Vis Sci. 2016;57:5586-92. 
41. Kifley A, Wang JJ, Cugati S, Wong TY, Mitchell P. Retinal vascular caliber, diabetes, and retinopathy. Am J Ophthalmol. 2007;143:1024-6.

42. Kifley A, Wang JJ, Cugati S, Wong TY, Mitchell P. Retinal vascular caliber and the long-term risk of diabetes and impaired fasting glucose: the Blue Mountains eye study. Microcirculation. 2008;15:373-7.

43. Klein R, Klein BE, Moss SE, Wong TY. Retinal vessel caliber and microvascular and macrovascular disease in type 2 diabetes: XXI: the Wisconsin epidemiologic study of diabetic retinopathy. Ophthalmology. 2007;114: 1884-92.

44. Klein R, Klein BE, Moss SE, et al. The relation of retinal vessel caliber to the incidence and progression of diabetic retinopathy: XIX: the Wisconsin epidemiologic study of diabetic retinopathy. Arch Ophthalmol. 2004;122:76-83.

45. Klein R, Myers CE, Lee KE, Gangnon R, Klein BE. Changes in retinal vessel diameter and incidence and progression of diabetic retinopathy. Arch Ophthalmol. 2012:130:749-55.

46. Roy MS, Klein R, Janal MN. Retinal venular diameter as an early indicator of progression to proliferative diabetic retinopathy with and without high-risk characteristics in African Americans with type 1 diabetes mellitus. Arch Ophthalmol. 2011;129:8-15.

47. Tsai AS, Wong TY, Lavanya R, et al. Differential association of retinal arteriolar and venular caliber with diabetes and retinopathy. Diabetes Res Clin Pract. 2011:94:291-8.

48. Sasongko MB, Wong TY, Nguyen TT, Cheung CY, Shaw JE, Wang JJ. Retinal vascular tortuosity in persons with diabetes and diabetic retinopathy. Diabetologia. 2011;54:2409-16.

49. Curtis TM, Gardiner TA, Stitt AW. Microvascular lesions of diabetic retinopathy: clues towards understanding pathogenesis? Eye (Lond). 2009; 23:1496-508.

50. Dobrin PB, Schwarcz TH, Baker WH. Mechanisms of arterial and aneurysmal tortuosity. Surgery. 1988;104:568-71.

51. Gould DB, Phalan FC, van Mil SE, et al. Role of COL4A1 in small-vessel disease and hemorrhagic stroke. N Engl J Med. 2006;354:1489-96.

52. Jensen RA, Sim X, Smith AV, et al. Novel genetic loci associated with retinal microvascular diameter. Circ Cardiovasc Genet. 2016;9:45-54.

53. Tandon A, Chen CJ, Penman A, et al. African ancestry analysis and admixture genetic mapping for proliferative diabetic retinopathy in African Americans. Invest Ophthalmol Vis Sci. 2015:56:3999-4005.

54. Penman A, Hancock H, Papavasileiou E, et al. Risk factors for proliferative diabetic retinopathy in African Americans with type 2 diabetes. Ophthalmic Epidemiol. 2016;23:88-93.

55. Penman A, Hoadley S, Wilson JG, Taylor HA, Chen CJ, Sobrin L. P-selectin plasma levels and genetic variant associated with diabetic retinopathy in African Americans. Am J Ophthalmol. 2015;159:1152-60 e1152.

56. Kristjansdottir JV, Hardarson SH, Halldorsson GH, Karlsson RA, Eliasdottir TS, Stefansson E. Retinal oximetry with a scanning laser ophthalmoscope. Invest Ophthalmol Vis Sci. 2014;55:3120-6.

57. Vehmeijer WB, Magnusdottir V, Eliasdottir TS, Hardarson SH, Schalij-Delfos $\mathrm{NE}$, Stefansson E. Retinal Oximetry with scanning laser ophthalmoscope in infants. PLoS One. 2016;11:e0148077.

\section{Publisher's Note}

Springer Nature remains neutral with regard to jurisdictional claims in published maps and institutional affiliations.

Ready to submit your research? Choose BMC and benefit from:

- fast, convenient online submission

- thorough peer review by experienced researchers in your field

- rapid publication on acceptance

- support for research data, including large and complex data types

- gold Open Access which fosters wider collaboration and increased citations

- maximum visibility for your research: over $100 \mathrm{M}$ website views per year

At $\mathrm{BMC}$, research is always in progress.

Learn more biomedcentral.com/submissions 